\title{
Association between Depressive Symptoms and Vitamin D Deficiency in Adults with Overweight or Obesity
}

\author{
Hee Chan Chung, MD', Young-Eun Jung, MD, PhD², Chanwon Park ${ }^{3}$, Moon-Doo Kim, MD, PhD², \\ Bo-Hyun Yoon, MD, PhD ${ }^{1}$
}

${ }^{1}$ Department of Psychiatry, Naju National Hospital, Naju, ${ }^{2}$ Department of Psychiatry, College of Medicine, Jeju National University, ${ }^{3}$ College of Medicine, Jeju National University, Jeju, Korea

\begin{abstract}
Background: The relationship between a low vitamin D level and depression has been demonstrated repeatedly. We assessed the correlation between vitamin D status and the prevalence of depression according to body weight status. Methods: Data from 1,747 participants who took part in the 2014 Korean National Health and Nutrition Examination Survey were analyzed. The presence of depression was identified by the brief, self-reported Patient Health Questionnaire-9 (PHQ-9), vitamin D status was defined based on the serum 25-hydroxyvitamin D [25(OH)D] level, and body weight status was expressed as the body mass index.

Results: After adjusting for potential confounding factors, participants in the vitamin $\mathrm{D}$ deficiency group (odds ratio $[\mathrm{OR}], 2.70 ; 95 \%$ confidence interval $[\mathrm{Cl}], 1.01-7.20)$ and severe deficiency group (OR, 2.89; $95 \% \mathrm{Cl}, 1.04-8.00)$ were significantly more likely to experience depression. Multivariate logistic regression analyses indicated that among the participants with overweight or obesity, those in the vitamin $\mathrm{D}$ deficiency group were 3.71 times more likely than those in the sufficiency group (OR, $3.71 ; 95 \% \mathrm{Cl}, 1.08-12.74)$ to experience depression.

Conclusion: Our findings suggest a significant association between low vitamin $\mathrm{D}$ levels and depression in adults with overweight or obesity. Further studies are needed to elucidate the association between vitamin D status and depression according to body weight status.
\end{abstract}

Keywords Vitamin D; Depression; Overweight; Obese

\section{INTRODUCTION}

Vitamin D is a fat-soluble vitamin involved in the metabolism of bone minerals, such as calcium and phosphorus [1-3], and is critical to skeletal development and growth. In addition to its role in calcium and bone homeostasis, recent work has suggested that vitamin D is also important for the regulation of many other cellular functions. After the 1,25-dihydroxyvitamin D3 receptor and 1alpha-hydroxylase, the enzyme responsible for the formation of the active vitamin in the human brain, were reported [4], the hypothesis that vitamin D may have autocrine/paracrine properties in the human brain was suggested. Based on that research, associations between vitamin $\mathrm{D}$ and psychiatric diseases, such as autism spectrum disorder [5-7], bipolar disorder [8,9], schizophrenia $[10,11]$, and depressive disorder [12], have been examined.

Among these disorders, depression is strongly associated with significant disability, mortality, and healthcare costs. Indeed, it is the third leading cause of disability in high-income countries [13]. Although biological, psychological, and environmental theories have been advanced, the underlying pathophysiology of depression has yet to be fully elucidated. Vitamin D has been suggested to prevent the onset of depression by activating

Received June 4, 2021, Revised July 5, 2021, Accepted July 5, 2021

Correspondence: Young-Eun Jung, MD, PhD

Department of Psychiatry, College of Medicine, Jeju National University, 15 Aran 13-gil, Jeju 63241, Korea

TEL +82-64-717-1234 FAX +82-64-717-1849 E-mail jyejye77@daum.net ORCID https://orcid.org/0000-0001-7608-0009

Copyright (c) by Korean Society for Affective Disorders.

This is an Open Access article distributed under the terms of the Creative Commons Attribution Non-Commercial License (http://creativecommons.org/licenses/ by-nc/4.0/) which permits unrestricted non-commercial use, distribution, and reproduction in any medium, provided the original work is properly cited. 
a number of processes critical to maintaining healthy neurons, including calcium homeostasis. Furthermore, increasing pathophysiological evidence shows that vitamin D deficiency is associated with depression [14].

Some studies have indicated no relationship between vitamin D and depression [15-18], whereas others have demonstrated a strong relationship, suggesting that subjects with low serum 25-hydroxyvitamin D [25(OH)D] levels are more likely to experience depression [19-21]. In a large population-based study using data from the third National Health and Nutrition Examination Survey in the United States, the likelihood of having depression was significantly higher in persons with vitamin D deficiency compared to those with vitamin D sufficiency [22]. By contrast, based on the same data, no significant association was found between serum concentrations of $25(\mathrm{OH}) \mathrm{D}$ and the presence of moderate to severe depression [17]. Also, results from previous studies examining the relationship between vitamin D supplementation and treatment outcomes in patients with depression have been equivocal. Some studies found that vitamin D supplementation did not reduce depressive symptoms [12,23-27], while others suggested that it did, especially in patients with major depressive disorder and individuals with vitamin D deficiency [28-32]. Therefore, further research is needed to clarify the relationship between vitamin $\mathrm{D}$ status and depression. Data on the association between vitamin $\mathrm{D}$ and depression are scarce. Furthermore, the association between these variables according to body weight has rarely been studied, although body weight may affect vitamin D status or vice versa [33-35].

The present study aimed to investigate the relationship between vitamin $\mathrm{D}$ status and the severity of depression, and to determine how that relationship changes with body weight status.

\section{MATERIALS AND METHODS}

\section{Participants}

This study used data from the sixth Korean National Health and Nutrition Examination Survey (KNHANES) conducted in 2014. The KNHANES is a nationwide, population-based, and cross-sectional health examination survey that has been conducted every year since 1998 by the Division of Chronic Disease Surveillance of the Korea Centers for Disease Control and Preven- tion, Ministry of Health and Welfare. It was designed to monitor the general health and nutrition status of the non-institutionalized civilian population of South Korea [36]. Every year, 8,000 to 10,000 individuals from 4,600 households are selected as a representative sample of Koreans. A multi-stage, clustered and stratified random sampling method is used. The survey comprises three individual measures: a health interview, a nutrition survey, and a health examination survey. The data are collected through household interviews and standardized physical examinations conducted at mobile examination centers. The KNHANES database is publicly available at the KNHANES website.

A total of 9,701 individuals were targeted for the 2014 KNHANES, 7,550 of whom participated in the survey. Of these participants, 5,976 were aged 19 years or older, and serum 25(OH)D levels were measured in 2,018 individuals. There were 192 participants with missing data, and 265 with depression currently on antidepressant medication; all were excluded. Ultimately, we analyzed the data of 1,747 participants. The KNHANES (2014) was approved by the Korea Centers for Disease Control and Prevention Institutional Review Board (approval number: 2013-07CON-03-4C, 2013-12EXP-03-5C), and the methods were in accordance with all approved guidelines. This study complied with the Personal Information Protection Act and Statistics Act, and only nondiscriminable de-identified data were used.

\section{Assessment}

The presence of depression was identified using the Patient Health Questionnaire-9 (PHQ-9), which is a reliable and valid tool for measuring depression severity over the previous 2 weeks [37]. The PHQ-9 is composed of nine items, each rated from 0 (not at all) to 3 (symptoms nearly every day); the scores for all items are summed to produce a total depression severity score (range: 0-27). The Korean version of the PHQ-9 has high internal consistency (Cronbach's $\alpha=0.86$ ), and the optimal cutoff total score for the presence of depression is 5 [38]. The suggested cutoff for mild, moderate, moderately severe, and severe depressive symptoms are 5, 10, 15 , and 20 points, respectively [37].

Currently, 25(OH)D is considered a reliable indicator of vitamin D status [39]. To measure the serum $25(\mathrm{OH})$ D level, blood samples were taken after participants had fasted for $\geq 8$ hours, and were analyzed within 24 hours 
of transport. Serum 25(OH)D levels were measured by radioimmunoassay (Diasorin, Stillwater, MN, USA) using a gamma counter (1470 Wizard Gamma Counter; Perkin Elmer, Turku, Finland). To minimize analytical variation, serum $25(\mathrm{OH}) \mathrm{D}$ levels were analyzed at the same institute, and a quality assurance program was implemented throughout the analysis period. Sufficient vitamin D status was defined as serum $25(\mathrm{OH}) \mathrm{D}>30$ $\mathrm{ng} / \mathrm{mL}$, and vitamin D insufficiency as a level of $>20 \mathrm{ng} /$ $\mathrm{mL}$ and $\leq 30 \mathrm{ng} / \mathrm{mL}$. Vitamin D deficiency was defined as serum $25(\mathrm{OH}) \mathrm{D} \leq 20 \mathrm{ng} / \mathrm{mL}$, with severe deficiency defined as $<10 \mathrm{ng} / \mathrm{mL}$ according to general guidelines [39].

Weight and height were measured using standardized procedures, and body mass index (BMI) was calculated as the weight in kilograms divided by the square of height in meters. Body weight status was determined by BMI; BMI values of $<18.5,18.5$ to $<23,23$ to $<25$, and $\geq 25 \mathrm{~kg} / \mathrm{m}^{2}$ have been accepted as the cutoff points defining underweight, normal weight, overweight, and obesity, respectively, in Asian populations [40].

Lifestyle factors included current smoking, alcohol use problems, and physical activity. In terms of smoking status, participants were categorized as current smokers or non-smokers. To obtain information on the severity of alcohol use problems, we administered the Alcohol Use Disorder Identification Test-Alcohol Consumption (AUDIT-C) instrument [41]. We used a cutoff score of 8 for significant alcohol use problems. Physical activity was determined according to metabolic equivalent of task (MET) values based on the self-reported frequency and duration of vigorous activity, moderate activity, and walking during the previous week. The MET value of a particular activity (vigorous activity $=8.0 \mathrm{MET}$; moderate activity=4.0 MET; walking=3.3 MET) was multiplied by the mean time (hours/week) spent performing that activity to calculate the MET-hours per week, and the total weekly physical activity was the sum of the weekly MET-hours for each activity [42].

The presence of chronic illness was determined based on a self-reported clinical diagnosis by a physician, and included the following diseases: diabetes mellitus, stroke, ischemic heart disease, renal failure, chronic hepatitis, and cancer. Serum creatinine was measured using the colorimetric method (Automatic Analyzer 7600; Hitachi, Tokyo, Japan), and the glomerular filtration rate (GFR) was then calculated using the Modification of Diet in Renal Disease (MDRD) method [43].

\section{Statistical analysis}

As the KNHANES data were acquired using stratified, clustered systematic sampling, complex sample analyses were performed based on an analysis plan involving weights, stratification variables, and primary sampling units. Missing data were included in the complex sample analyses to produce nationally representative estimates with accurate variance data. A general linear model and chi-square tests were performed to determine the significance of differences in variables after dividing participants into two groups based on the presence of depression. In addition, the prevalence and severity of depression were analyzed according to four vitamin $\mathrm{D}$ levels. To determine the associations between depression (independent variable) and vitamin D status (dependent variable), complex simple logistic regression analysis was performed to calculate the adjusted odds ratios (ORs) and 95\% confidence intervals (CIs). Possible confounding factors were adjusted for in the multivariable model, including age, sex, marital status, income, current smoking, alcohol use problems, physical activity, body weight status, chronic illness, and GFR. The analyses were stratified by body weight, as this variable showed significant differences in the univariate analysis by depression status, and is a known effect modifier. Statistical analyses were performed using SPSS software (version 25.0; IBM Corp., Armonk, NY, USA), and $p$-value $<0.05$ was taken to indicate statistical significance.

\section{RESULTS}

Table 1 shows the general characteristics of the study participants with and without depression. Of the 1,747 participants included in the cross-sectional analyses, 361 exhibited the presence of depression, for a prevalence of $20.7 \%$. The prevalence of vitamin D deficiency, defined as a serum $25(\mathrm{OH}) \mathrm{D}$ level $\leq 20 \mathrm{ng} / \mathrm{mL}$, was $77.3 \%$ among the study participants (deficiency, 61.9\%; severe deficiency, $15.4 \%)$. The mean serum $25(\mathrm{OH}) \mathrm{D}$ concentration was $14.8 \pm 0.4 \mathrm{ng} / \mathrm{mL}$ and $16.0 \pm 0.3 \mathrm{ng} / \mathrm{mL}$ in depressed and non-depressed participants, respectively $(\mathrm{p}=0.001)$. Depressed participants were younger $(p=0.002)$ and more likely to be female $(\mathrm{p}<0.001)$ compared to nondepressed participants. Depressed participants were more likely to have lower education levels, although this 
Table 1. Characteristics of the study population

\begin{tabular}{|c|c|c|c|}
\hline Variable & $\begin{array}{l}\text { Depressed participants }{ }^{a} \\
\qquad(n=361)\end{array}$ & $\begin{array}{l}\text { Non-depressed participants } \\
\qquad(n=1,386)\end{array}$ & $\mathrm{p}$-value \\
\hline Serum 25(OH)D (ng/mL) & $14.8 \pm 0.4$ & $16.0 \pm 0.3$ & $0.001 *$ \\
\hline Age (y) & $40.1 \pm 0.8$ & $42.7 \pm 0.4$ & $0.002 \star$ \\
\hline Sex, female & $243(61.7)$ & $664(47.9)$ & $<0.001 *$ \\
\hline Education & & & 0.246 \\
\hline >High school & $115(34.2)$ & $523(37.8)$ & \\
\hline$<$ High school & $246(65.8)$ & $863(62.2)$ & \\
\hline Marital status & & & $0.005 *$ \\
\hline Married, living together & $208(58.6)$ & 972 (66.9) & \\
\hline Divorced/separated/widowed & $44(9.6)$ & $97(5.3)$ & \\
\hline Not married & $108(31.8)$ & $316(27.7)$ & \\
\hline Income, $\leq 25$ th percentile & $59(14.4)$ & $135(8.3)$ & $<0.001 *$ \\
\hline Current smoking & $96(30.3)$ & $325(26.7)$ & 0.267 \\
\hline Alcohol use problems & $73(24.2)$ & 285 (24.9) & 0.805 \\
\hline Physical activity (MET/h/wk) & & & 0.208 \\
\hline$<5.0$ & $88(23.2)$ & $269(18.1)$ & \\
\hline 5.0 to $<20.0$ & $115(31.1)$ & $484(34.7)$ & \\
\hline 20.0 to $<50.0$ & $88(25.4)$ & $379(27.6)$ & \\
\hline$\geq 50.0$ & $70(20.3)$ & $252(19.6)$ & \\
\hline Chronic illness, yes & $36(8.7)$ & $137(8.4)$ & 0.901 \\
\hline MDRD-estimated GFR $\left(\mathrm{mL} / \mathrm{min} / 1.73 \mathrm{~m}^{2}\right)$ & $100.2 \pm 1.1$ & $98.1 \pm 0.5$ & 0.070 \\
\hline Body weight status & & & $<0.001 *$ \\
\hline Obese & $101(26.0)$ & $470(33.2)$ & \\
\hline Overweight & $65(19.8)$ & $310(22.6)$ & \\
\hline Underweight & $35(8.8)$ & $51(3.8)$ & \\
\hline Normal & $160(45.3)$ & $555(40.4)$ & \\
\hline
\end{tabular}

Values are presented as mean \pm standard error or number (\%). The unweighted numbers and weighted percentage distributions are shown. Different subtotal because of missing.

25(OH)D, 25-hydroxyvitamin D; MET, metabolic equivalent of task; GFR, glomerular filtration rate; MDRD, Modification of Diet in Renal Disease.

${ }^{\mathrm{a}}$ The presence of depression was defined as total score on the Patient Health Questionnaire-9 (PHQ-9) $\geq 5$.

*Statistically significant difference.

difference was not statistically significant. Depressed participants were less likely to be married or cohabiting, and more likely to be divorced/separated/widowed or not married $(p=0.005)$. Overweight/obese participants were less likely to be depressed, whereas underweight and normal weight participants were more likely to exhibit depression $(\mathrm{p}<0.001)$.

Table 2 shows the relationships of vitamin D status with severity of depression and mean total PHQ-9 scores. Participants were categorized into four groups according to the blood levels of serum 25(OH)D (severe deficiency, deficiency, insufficiency, sufficiency) and severity of depression (severe, moderate, mild, no). Serum vitamin D levels exhibited negative relationships with depression severity $(\mathrm{p}=0.036)$ and PHQ-9 total score $(\mathrm{p}=0.020)$. Table 3 shows the OR for depression based on serum vitamin D status. The analyses were adjusted for age, sex, marital status, income, current smoking, alcohol use problems, physical activity, body weight, chronic illness, and GFR. The OR for the vitamin D deficiency group relative to the sufficiency group was 2.63 (95\% CI, 1.13-6.11) before and 2.70 (95\% CI, 1.017.20) after adjustment; both differences were statistically significant. The OR for the severe vitamin D deficiency group relative to the sufficiency group was 3.35 (95\% CI, 1.38-8.09) before and 2.89 (95\% CI, 1.04-8.00) after adjustment, which were also statistically significant.

The results of our secondary analysis, which stratified 
Table 2. Severity of depression by vitamin D status

\begin{tabular}{|c|c|c|c|c|c|}
\hline \multirow[b]{2}{*}{ Variable } & \multicolumn{4}{|c|}{ Vitamin D status $^{\mathrm{a}}$} & \multirow[b]{2}{*}{$\mathrm{p}$-value } \\
\hline & $\begin{array}{l}\text { Severe deficiency } \\
\quad(n=269)\end{array}$ & $\begin{array}{l}\text { Deficiency } \\
(n=1,081)\end{array}$ & $\begin{array}{l}\text { Insufficiency } \\
\quad(n=338)\end{array}$ & $\begin{array}{l}\text { Sufficiency } \\
\qquad(n=59)\end{array}$ & \\
\hline Severity of depression ${ }^{b}$ & & & & & $0.036 *$ \\
\hline No $(n=1,386)$ & $201(75.7)$ & $850(79.8)$ & $283(83.3)$ & $52(91.2)$ & \\
\hline Mild $(n=273)$ & 49 (17.7) & $178(15.6)$ & $39(11.8)$ & 7 (8.8) & \\
\hline Moderate $(n=68)$ & $12(4.1)$ & $45(3.9)$ & $11(3.0)$ & $0(0.0)$ & \\
\hline Severe $(n=20)$ & $7(2.5)$ & $8(0.6)$ & $5(1.8)$ & $0(0.0)$ & \\
\hline PHQ-9 total score & $3.09 \pm 0.27$ & $2.52 \pm 0.10$ & $2.47 \pm 0.23$ & $1.85 \pm 0.27$ & $0.020 *$ \\
\hline
\end{tabular}

Values are presented as number (\%) or mean \pm standard error. The unweighted numbers and weighted percentage distributions are shown. PHQ-9, Patient Health Questionnaire-9.

${ }^{a}$ Severe vitamin $D$ deficiency was defined as serum $25(\mathrm{OH}) \mathrm{D}<10.0 \mathrm{ng} / \mathrm{mL}$, deficiency as $\leq 20.0 \mathrm{ng} / \mathrm{mL}$, insufficiency as $>20.0 \mathrm{ng} / \mathrm{mL}$ and $\leq 30.0 \mathrm{ng} / \mathrm{mL}$, and sufficiency as $>30.0 \mathrm{ng} / \mathrm{mL}$.

${ }^{\mathrm{b}}$ The severity of depression was defined by the distribution of the Patient Health Queistionnaire-9 (PHQ-9) with 0-4 being no, 5-9 being mild, 10-14 being moderate, and 15-27 being severe depression.

*Statistically significance difference.

Table 3. Risks of depression according to vitamin D status

\begin{tabular}{|c|c|c|}
\hline \multirow[b]{2}{*}{ Vitamin D status $^{\mathrm{a}}$} & \multicolumn{2}{|c|}{ Total } \\
\hline & $\begin{array}{l}\text { Crude OR } \\
(95 \% \mathrm{Cl})\end{array}$ & $\begin{array}{l}\text { Adjusted OR } \\
(95 \% \mathrm{Cl})^{\mathrm{b}}\end{array}$ \\
\hline Sufficiency $(n=59)$ & 1.00 (reference) & 1.00 (reference) \\
\hline Insufficiency $(n=338)$ & $2.08(0.86-5.05)$ & $2.54(0.92-7.03)$ \\
\hline Deficiency $(n=1,081)$ & $2.63(1.13-6.11) \star$ & $2.70(1.01-7.20) *$ \\
\hline $\begin{array}{l}\text { Severe deficiency } \\
\qquad(n=269)\end{array}$ & $3.35(1.38-8.09) \star$ & $2.89(1.04-8.00) \star$ \\
\hline
\end{tabular}

$\mathrm{OR}$, odds ratio; $\mathrm{Cl}$, confidence interval.

${ }^{a}$ Severe vitamin D deficiency was defined as serum $25(\mathrm{OH}) \mathrm{D}<10$ $\mathrm{ng} / \mathrm{mL}$, deficiency as $\leq 20 \mathrm{ng} / \mathrm{mL}$, insufficiency as $>20 \mathrm{ng} / \mathrm{mL}$ and $\leq 30 \mathrm{ng} / \mathrm{mL}$, and sufficiency as $>30 \mathrm{ng} / \mathrm{mL}$.

${ }^{b}$ Adjusted for age, sex, marital status, income, current smoking, alcohol use problems, physical activity, body weight status, chronic illness, and glomerular filtration rate.

*Statistically significance difference.

subjects by body weight status, are shown in Table 4. In the fully adjusted model, which included age, sex, marital status, income, current smoking, alcohol use problems, physical activity, chronic illness, and GFR, the association between low vitamin D status and depression was significant only in overweight/obese participants. Among the overweight and obese participants, those with vitamin D deficiency were 3.71 times more likely to exhibit depression than those in the sufficiency group (OR, 3.71; 95\% CI, 1.08-12.74).

\section{DISCUSSION}

We conducted a cross-sectional study in the Korean adult population and examined the association between vitamin D status and depression, as well changes in this association by body weight status. This study had the advantage of using KNHANES data, which are reliable and nationally representative of the health of the general adult Korean population.

We found that $20.7 \%$ of participants exhibited depression (PHQ-9 score $\geq 5$ ); this percentage increased as the serum vitamin D level decreased. These findings were similar to a previous meta-analysis [44] and crosssectional studies worldwide $[22,45]$. The above results, which suggest that vitamin D plays a role in depression, cannot be regarded as definitive, as several studies found no association between vitamin D status and depression after controlling for various confounding factors [15,17,18,46]. Zhao et al. (2010) [17] conducted a large cross-sectional, population-based study of adults in the United States $(n=3,916)$, and found no significant association between serum 25(OH)D and depression after adjusting for confounding factors. In the fifth KNHANES, serum 25(OH)D levels were not significantly associated with depressive symptoms in Korean adults, but the analysis was limited in that depressive symptoms were assessed by a single question, i.e., "Have you felt sad or hopeless for at least 2 consecutive weeks during the past year to the extent that you had difficulty performing your usual activities?" [46]. 
Table 4 Risks of depression according to vitamin D status by body weight status

\begin{tabular}{|c|c|c|c|c|c|c|}
\hline \multirow{2}{*}{ Vitamin D status $^{a}$} & \multicolumn{3}{|c|}{ Normal or underweight $(n=801)$} & \multicolumn{3}{|c|}{ Overweight or obese $(n=946)$} \\
\hline & Total (n) & Depression (n) & Adjusted OR $(95 \% \mathrm{Cl})^{\mathrm{b}}$ & Total $(n)$ & Depression (n) & Adjusted OR $(95 \% \mathrm{Cl})^{\mathrm{b}}$ \\
\hline Sufficiency & 23 & 3 & 1.00 (reference) & 36 & 4 & 1.00 (reference) \\
\hline Insufficiency & 136 & 25 & $1.89(0.44-8.22)$ & 202 & 30 & $3.43(0.96-12.21)$ \\
\hline Deficiency & 510 & 123 & $2.03(0.51-8.05)$ & 571 & 108 & $3.71(1.08-12.74) *$ \\
\hline Severe deficiency & 132 & 44 & $2.89(0.68-12.23)$ & 137 & 24 & $2.62(0.74-9.33)$ \\
\hline
\end{tabular}

$\mathrm{OR}$, odds ratio; $\mathrm{Cl}$, confidence interval.

${ }^{a}$ Severe vitamin D deficiency was defined as serum $25(\mathrm{OH}) \mathrm{D}<10 \mathrm{ng} / \mathrm{mL}$, deficiency as $\leq 20 \mathrm{ng} / \mathrm{mL}$, insufficiency as $>20 \mathrm{ng} / \mathrm{mL}$ and $\leq 30 \mathrm{ng} /$ $\mathrm{mL}$, and sufficiency as $>30 \mathrm{ng} / \mathrm{mL}$.

${ }^{b}$ Adjusted for age, sex, marital status, income, current smoking, alcohol use problems, physical activity, chronic illness, and glomerular filtration rate.

*Statistically significance difference.

The present study found that low vitamin D was associated with depression. This result was consistent with a study of overweight and obese adults, which showed that participants with low 25(OH)D levels had a higher degree of depression [30]. A recent observational study on elderly individuals and a large study of US adults also demonstrated a relationship between 25(OH)D deficiency and depression [47,48]. Furthermore, we found that overweight/obese participants with vitamin D deficiency had significantly more severe depression than those with vitamin D sufficiency.

The relationship between vitamin D deficiency and the risk of depression in overweight/obese participants supports a protective effect of vitamin D against depression [14]. This result is consistent with findings linking obesity to lower vitamin D levels [33-35] and a lower likelihood of depression [49,50]. The statistically significant relationship between vitamin D status and depression seen in overweight/obese participants, but not in normal/underweight participants with vitamin $\mathrm{D}$ deficiency, might be due to individual factors that affect depression, such as nutritional status [51], stress level $[52,53]$, and average sleep time $[54,55]$. Further studies are required to clarify the association between vitamin D status and depression according to body weight, status and to examine potential underlying mechanisms.

Finally, our findings revealed that vitamin D deficiency is prevalent in Korea and seems to be more severe than in Western nations [56]. A total of $77.3 \%$ of our sample had vitamin D deficiency, defined as serum $25(\mathrm{OH}) \mathrm{D}$ below $20 \mathrm{ng} / \mathrm{mL}$, which is the minimum level of serum $25(\mathrm{OH}) \mathrm{D}$ required to minimize the risk of rickets [57]. Vitamin D deficiency is now well recog- nized as being a more common health problem in Asian countries. A variety of cultural, environmental, and genetic factors, such as Asians' darker skin, differences in dietary culture, and lower rates of vitamin D supplementation have been suggested as reasons for the lower vitamin D levels of Asian than Western populations [46]. Previous studies have shown that vitamin D is unique in that it is mostly acquired by cutaneous synthesis in response to sunlight exposure; dietary sources of vitamin D are minimal [56]. Therefore, with respect to the association between vitamin D status and depression, interventions such as vitamin $\mathrm{D}$ supplementation and behavior changes to increase sunlight exposure should be considered for depressed individuals at risk of vitamin D deficiency.

The main limitation of our study was its cross-sectional design, which prevented determination of a causal relationship between vitamin D status and depression, and analysis of how that relationship changed according to body weight status. The second limitation was that factors affecting vitamin D status, such as light exposure, working outdoors, vitamin D supplementation, use of UV blocking agents, season in which the study was performed, and individual eating habits were not included as potential confounding factors in our analysis, because such data were not available. The final limitation was that the level of depression was measured using only a self-rating questionnaire. The PHQ-9 has been well-validated as a screening tool for depression; however, it is not a diagnostic tool. Despite these limitations, we obtained meaningful results by analyzing the 2014 KNHANES database, given its large size and complex sampling method. We found that low vitamin D levels 
were significantly associated with depression in the Korean adult population.

\section{CONCLUSION}

The present study revealed a positive association between low vitamin $\mathrm{D}$ and the risk of depression, and also clarified the effects of body weight status on that relationship. The association between vitamin $\mathrm{D}$ deficiency and depression was more prominent in overweight/obese than underweight/normal weight adults. Further longitudinal studies are needed to clarify the causal relationship of vitamin D with depression according to body weight status. Also, research addressing the limitations of our study could provide more reliable results.

\section{CONFLICTS OF INTEREST}

The authors have nothing to disclose.

\section{ACKNOWLEDGEMENTS}

This work was supported by the 2021 education, research and student guidance grant funded by Jeju National University.

\section{ORCID}

\author{
Hee Chan Chung \\ https://orcid.org/0000-0002-7367-6699 \\ Young-Eun Jung \\ https://orcid.org/0000-0001-7608-0009 \\ Chanwon Park \\ https://orcid.org/0000-0001-5833-0959 \\ Moon-Doo Kim \\ https://orcid.org/0000-0002-6441-630X \\ Bo-Hyun Yoon \\ https://orcid.org/0000-0002-3882-7930
}

\section{REFERENCES}

1. Koo W, Walyat N. Vitamin D and skeletal growth and development. Curr Osteoporos Rep 2013;11:188-93.

2. Dusso AS, Brown AJ, Slatopolsky E. Vitamin D. Am J
Physiol Renal Physiol 2005;289:F8-28.

3. Bikle DD. Vitamin D metabolism, mechanism of action, and clinical applications. Chem Biol 2014;21:319-29.

4. Eyles DW, Smith S, Kinobe R, Hewison M, McGrath JJ. Distribution of the vitamin D receptor and 1 alpha-hydroxylase in human brain. J Chem Neuroanat 2005;29:21-30.

5. Vinkhuyzen AAE, Eyles DW, Burne THJ, Blanken LME, Kruithof CJ, Verhulst F, et al. Gestational vitamin D deficiency and autism-related traits: the Generation R Study. Mol Psychiatry 2018;23:240-6.

6. Petruzzelli MG, Marzulli L, Margari F, De Giacomo A, Gabellone A, Giannico OV, et al. Vitamin D deficiency in autism spectrum disorder: a cross-sectional study. Dis Markers 2020;2020:9292560.

7. Saad K, Abdel-Rahman AA, Elserogy YM, Al-Atram AA, Cannell JJ, Bjørklund G, et al. Vitamin D status in autism spectrum disorders and the efficacy of vitamin D supplementation in autistic children. Nutr Neurosci 2016;19:34651.

8. Cereda G, Enrico P, Ciappolino V, Delvecchio G, Brambilla $\mathrm{P}$. The role of vitamin $\mathrm{D}$ in bipolar disorder: epidemiology and influence on disease activity. J Affect Disord 2021;278:209-17.

9. Naifar M, Maalej Bouali M, Guidara W, Ellouze AS, Jmal K, Omri S, et al. [Bipolar disorder vulnerability: the vitamin D path]. Can J Psychiatry 2020;65:184-92. French.

10. Ahmadi S, Mirzaei K, Hossein-Nezhad A, Shariati G. Vitamin D receptor FokI genotype may modify the susceptibility to schizophrenia and bipolar mood disorder by regulation of dopamine D1 receptor gene expression. Minerva Med 2012;103:383-91.

11. Yan J, Feng J, Craddock N, Jones IR, Cook EH Jr, Goldman D, et al. Vitamin D receptor variants in 192 patients with schizophrenia and other psychiatric diseases. Neurosci Lett 2005;380:37-41.

12. Woo YS, Kim S, Jeong JH, Jung YE, Kim MD, Bahk WM. Vitamin D deficiency/insufficiency among inpatients with depressive symptoms. Clin Psychopharmacol Neurosci 2019;17:121-4.

13. Lopez AD, Mathers CD, Ezzati M, Jamison DT, Murray CJ. Global and regional burden of disease and risk factors, 2001: systematic analysis of population health data. Lancet 2006;367:1747-57.

14. Berridge MJ. Vitamin D and depression: cellular and regulatory mechanisms. Pharmacol Rev 2017;69:80-92.

15. Nanri A, Mizoue T, Matsushita Y, Poudel-Tandukar K, Sato M, Ohta M, et al. Association between serum 25-hydroxyvitamin D and depressive symptoms in Japanese: analysis by survey season. Eur J Clin Nutr 2009;63:1444-7.

16. Park JI, Yang JC, Park TW, Chung SK. Is serum 25-hydroxyvitamin D associated with depressive symptoms and suicidal ideation in Korean adults? Int J Psychiatry Med 2016;51:31-46.

17. Zhao G, Ford ES, Li C, Balluz LS. No associations between serum concentrations of 25-hydroxyvitamin D and 
parathyroid hormone and depression among US adults. Br J Nutr 2010;104:1696-702.

18. Pan A, Lu L, Franco OH, Yu Z, Li H, Lin X. Association between depressive symptoms and 25-hydroxyvitamin $\mathrm{D}$ in middle-aged and elderly Chinese. J Affect Disord 2009;118:240-3.

19. Milaneschi Y, Hoogendijk W, Lips P, Heijboer AC, Schoevers R, van Hemert AM, et al. The association between low vitamin D and depressive disorders. Mol Psychiatry 2014;19:444-51.

20. Ju SY, Lee YJ, Jeong SN. Serum 25-hydroxyvitamin D levels and the risk of depression: a systematic review and meta-analysis. J Nutr Health Aging 2013;17:447-55.

21. Anglin RE, Samaan Z, Walter SD, McDonald SD. Vitamin $\mathrm{D}$ deficiency and depression in adults: systematic review and meta-analysis. Br J Psychiatry 2013;202:100-7.

22. Ganji V, Milone C, Cody MM, McCarty F, Wang YT. Serum vitamin $\mathrm{D}$ concentrations are related to depression in young adult US population: the Third National Health and Nutrition Examination Survey. Int Arch Med 2010;3:29.

23. Vellekkatt F, Menon V. Efficacy of vitamin D supplementation in major depression: a meta-analysis of randomized controlled trials. J Postgrad Med 2019;65:74-80.

24. Hansen JP, Pareek M, Hvolby A, Schmedes A, Toft T, Dahl E, et al. Vitamin D3 supplementation and treatment outcomes in patients with depression (D3-vit-dep) BMC Res Notes 2019;12:203.

25. Pittampalli S, Mekala HM, Upadhyayula S, Lippmann S. Does vitamin D deficiency cause depression? Prim Care Companion CNS Disord 2018;20:17102263.

26. Cheng YC, Huang YC, Huang WL. The effect of vitamin D supplement on negative emotions: a systematic review and meta-analysis. Depress Anxiety 2020;37:549-64.

27. Jorde R, Sneve M, Figenschau Y, Svartberg J, Waterloo $\mathrm{K}$. Effects of vitamin D supplementation on symptoms of depression in overweight and obese subjects: randomized double blind trial. J Intern Med 2008;264:599-609.

28. Li G, Mbuagbaw L, Samaan Z, Falavigna M, Zhang S, Adachi JD, et al. Efficacy of vitamin D supplementation in depression in adults: a systematic review. J Clin Endocrinol Metab 2014;99:757-67.

29. Libuda L, Laabs BH, Ludwig C, Bühlmeier J, Antel J, Hinney A, et al. Vitamin D and the risk of depression: a causal relationship? Findings from a Mendelian randomization study. Nutrients 2019;11:1085.

30. Shaffer JA, Edmondson D, Wasson LT, Falzon L, Homma K, Ezeokoli N, et al. Vitamin D supplementation for depressive symptoms: a systematic review and meta-analysis of randomized controlled trials. Psychosom Med 2014;76:190-6.

31. de Koning EJ, Lips P, Penninx BWJH, Elders PJM, Heijboer AC, den Heijer M, et al. Vitamin D supplementation for the prevention of depression and poor physical function in older persons: the D-Vitaal study, a randomized clinical trial. Am J Clin Nutr 2019;110:1119-30.

32. Okereke OI, Reynolds CF 3rd, Mischoulon D, Chang G,
Vyas CM, Cook NR, et al. Effect of long-term vitamin D3 supplementation vs placebo on risk of depression or clinically relevant depressive symptoms and on change in mood scores: a randomized clinical trial. JAMA 2020;324:47180.

33. Jääskeläinen T, Männistö S, Härkänen T, Sääksjärvi K, Koskinen S, Lundqvist A. Does vitamin D status predict weight gain or increase in waist circumference? Results from the longitudinal Health 2000/2011 Survey. Public Health Nutr 2020;23:1266-72.

34. Ruiz-Ojeda FJ, Anguita-Ruiz A, Leis R, Aguilera CM. Genetic factors and molecular mechanisms of vitamin D and obesity relationship. Ann Nutr Metab 2018;73:89-99.

35. Sergeev IN. Vitamin D status and vitamin D-dependent apoptosis in obesity. Nutrients 2020;12:1392.

36. Kweon S, Kim Y, Jang MJ, Kim Y, Kim K, Choi S, et al. Data resource profile: the Korea National Health and Nutrition Examination Survey (KNHANES). Int J Epidemiol 2014;43:69-77.

37. Kroenke K, Spitzer RL, Williams JB. The PHQ-9: validity of a brief depression severity measure. J Gen Intern Med 2001;16:606-13.

38. Han C, Jo SA, Kwak JH, Pae CU, Steffens D, Jo I, et al. Validation of the Patient Health Questionnaire-9 Korean version in the elderly population: the Ansan Geriatric study. Compr Psychiatry 2008;49:218-23

39. Holick MF, Binkley NC, Bischoff-Ferrari HA, Gordon CM, Hanley DA, Heaney RP, et al. Evaluation, treatment, and prevention of vitamin D deficiency: an Endocrine Society clinical practice guideline. J Clin Endocrinol Metab 2011;96:1911-30.

40. Kanazawa M, Yoshiike N, Osaka T, Numba Y, Zimmet P, Inoue S. Criteria and classification of obesity in Japan and Asia-Oceania. World Rev Nutr Diet 2005;94:1-12.

41. Gordon AJ, Maisto SA, McNeil M, Kraemer KL, Conigliaro RL, Kelley ME, et al. Three questions can detect hazardous drinkers. J Fam Pract 2001;50:313-20.

42. Ainsworth BE, Haskell WL, Whitt MC, Irwin ML, Swartz AM, Strath SJ, et al. Compendium of physical activities: an update of activity codes and MET intensities. Med Sci Sports Exerc 2000;32(9 Suppl):S498-504.

43. Levey AS, Bosch JP, Lewis JB, Greene T, Rogers N, Roth D. A more accurate method to estimate glomerular filtration rate from serum creatinine: a new prediction equation. Modification of Diet in Renal Disease Study Group. Ann Intern Med 1999;130:461-70.

44. Okereke OI, Singh A. The role of vitamin D in the prevention of late-life depression. J Affect Disord 2016;198:1-14.

45. Chu F, Ohinmaa A, Klarenbach S, Wong ZW, Veugelers P. Serum 25-hydroxyvitamin D concentrations and indicators of mental health: an analysis of the Canadian health measures survey. Nutrients 2017;9:1116.

46. Park JH, Hong IY, Chung JW, Choi HS. Vitamin D status in South Korean population: seven-year trend from the KNHANES. Medicine (Baltimore) 2018;97:e11032. 
47. Hoang MT, Defina LF, Willis BL, Leonard DS, Weiner MF, Brown ES. Association between low serum 25-hydroxyvitamin D and depression in a large sample of healthy adults: the Cooper Center longitudinal study. Mayo Clin Proc 2011;86:1050-5.

48. Stewart R, Hirani V. Relationship between vitamin D levels and depressive symptoms in older residents from a national survey population. Psychosom Med 2010;72:608-12.

49. Rao WW, Zong QQ, Zhang JW, An FR, Jackson T, Ungvari GS, et al. Obesity increases the risk of depression in children and adolescents: results from a systematic review and meta-analysis. J Affect Disord 2020;267:78-85.

50. Luppino FS, de Wit LM, Bouvy PF, Stijnen T, Cuijpers P, Penninx BW, et al. Overweight, obesity, and depression: a systematic review and meta-analysis of longitudinal studies. Arch Gen Psychiatry 2010;67:220-9.

51. Kaner G, Soylu M, Yüksel N, Inanç N, Ongan D, Başmısırlı E. Evaluation of nutritional status of patients with depression. Biomed Res Int 2015;2015:521481.

52. Gold PW, Machado-Vieira R, Pavlatou MG. Clinical and biochemical manifestations of depression: relation to the neurobiology of stress. Neural Plast 2015;2015:581976.

53. Kessler RC, McGonagle KA, Zhao S, Nelson CB, Hughes M, Eshleman S, et al. Lifetime and 12-month prevalence of DSM-III-R psychiatric disorders in the United States. Results from the National Comorbidity Survey. Arch Gen Psychiatry 1994;51:8-19.

54. Zhai L, Zhang H, Zhang D. Sleep duration and depression among adults: a meta-analysis of prospective studies. Depress Anxiety 2015;32:664-70.

55. Difrancesco S, Lamers F, Riese H, Merikangas KR, Beekman ATF, van Hemert AM, et al. Sleep, circadian rhythm, and physical activity patterns in depressive and anxiety disorders: a 2-week ambulatory assessment study. Depress Anxiety 2019;36:975-86.

56. Holick MF. The vitamin D deficiency pandemic: approaches for diagnosis, treatment and prevention. Rev Endocr Metab Disord 2017;18:153-65.

57. Holick MF. Vitamin D deficiency. N Engl J Med 2007;357: 266-81. 